\title{
CLINICAL, RADIOLOGICAL AND BIOCHEMICAL CORRELATION FOR USING MRCP AS A DIAGNOSTIC TOOL IN OBSTRUCTIVE JAUNDICE
}

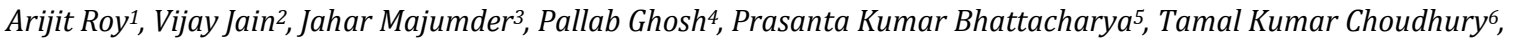 \\ Siddhartha Chakraborty ${ }^{7}$
}

\author{
${ }^{1}$ Assistant Professor, Department of Surgery, KPC Medical College and Hospital, Kolkata. \\ ${ }^{2}$ Associate Professor, Department of Surgery, KPC Medical College and Hospital, Kolkata. \\ ${ }^{3}$ Professor, Department of Surgery, KPC Medical College and Hospital, Kolkata. \\ ${ }^{4}$ Professor, Department of Surgery, KPC Medical College and Hospital, Kolkata. \\ ${ }^{5}$ Professor, Department of Plastic Surgery, KPC Medical College and Hospital, Kolkata. \\ ${ }^{6}$ Professor, Department of Surgery, KPC Medical College and Hospital, Kolkata. \\ 7 Professor, Department of Cardiothoracic and Vascular Surgery, KPC Medical College and Hospital, Kolkata.
}

\section{ABSTRACT}

\section{BACKGROUND}

Symptomatic cholelithiasis is a common medical problem, which makes cholecystectomy one of the most frequently performed surgical procedures in the world. Choledocholithiasis complicates the workup and management of cholelithiasis, necessitates additional diagnostic and therapeutic procedures, and adds to the morbidity and mortality of gallstone disease. Ultrasound fails to detect a CBD stone in a jaundiced patient with elevated liver enzymes in about $50 \%-75 \%$ cases; although it may detect dilatation of the CBD or the intrahepatic biliary radicals. ERCP is a good diagnostic and therapeutic tool to detect CBD stones; but it has its own set of complications such as trauma, haemorrhage, cholangitis and pancreatitis. MRCP is a very good diagnostic tool with very high sensitivity; but is very expensive and cannot be recommended for all cases of cholelithiasis.

So this study was undertaken to identify patients; in a cost effective manner; with cholelithiasis who required a pre-operative MRCP and to see its sensitivity and specificity.

\section{MATERIALS AND METHODS}

All patients, admitted with acute or chronic cholecystitis in the Department of Surgery, KPC Medical College and Hospital between 01.07.2015 and 31.12.2016 (18 Months) were investigated after a thorough clinical examination with biochemical liver function tests and ultrasonography. Magnetic Resonance Cholangiopancreatography (MRCP) was done only in selected cases. An evaluation of the sensitivity and specificity of MRCP was done and conclusions were drawn regarding the routine/selective use of the above investigation in patients of cholelithiasis.

\section{RESULTS}

Although very effective, performing an MRCP on all patients who were to undergo cholecystectomy is not cost effective and waste of resources. The positive predictive value is about 7.8\% (according to our study) in such a situation. But when MRCP was done only in selected patients, i.e. those with clinical, radiological and biochemical risk factors for CBD stones the positive predictive value was found to be $88.23 \%$ in our study. The sensitivity and specificity of MRCP was found to be $100 \%$.

\section{CONCLUSION}

MRCP is a very good diagnostic tool for imaging the CBD and when used within its defined criteria has a very high positive predictive value $(88.23 \%$ in our study) for CBD stones. Subjecting all patients of cholelithiasis to further expensive investigations (MRCP) for associated choledocholithiasis is unnecessary and not cost effective. Only those patients satisfying the well-defined criteria as postulated in the study may be investigated for associated choledocholithiasis.

\section{KEYWORDS}

Obstructive Jaundice, ERCP, MRCP, Choledocholithiasis.

HOW TO CITE THIS ARTICLE: Roy A, Jain V, Majumder J, et al. Clinical, radiological and biochemical correlation for using MRCP as a diagnostic tool in obstructive jaundice. J. Evolution Med. Dent. Sci. 2017;6(39):3118-3123, DOI: 10.14260/Jemds/2017/672

\section{BACKGROUND}

Choledocholithiasis is one of the most commonly encountered clinical entities and also one of the most commonly missed; which is most unfortunate as it is a potentially curable condition.

Financial or Other, Competing Interest: None.

Submission 10-04-2017, Peer Review 04-05-2017,

Acceptance 10-05-2017, Published 15-05-2017.

Corresponding Author:

Dr. Arijit Roy,

KPC Medical College and Hospital,

$1 F$, Raja SC Mallick Road, Kolkata-700032.

E-mail: drarijitroy7@gmai.com

DOI: $10.14260 /$ jemds $/ 2017 / 672$
The typical features of pain, fever and jaundice due to cholangitis in CBD obstruction may not be present in all cases of choledocholithiasis; whereas in others the liver functions may be normal. Ultrasound fails to detect a CBD stone in a jaundiced patient with elevated liver enzymes in about $50 \%$ $75 \%$ cases, $[1],[2]$ although it may detect dilatation of the CBD or the intrahepatic biliary radicals. [3] ERCP is a good diagnostic and therapeutic tool to detect CBD stones; but it has its own set of complications such as trauma, haemorrhage, cholangitis and pancreatitis. MRCP is a very good diagnostic tool with very high sensitivity; but is very expensive and cannot be recommended for all cases of cholelithiasis. So, this study was undertaken to identify patients with cholelithiasis who required a pre-operative MRCP and to ascertain its sensitivity and specificity. 
Even with the most modern equipment, the sensitivity for choledocholithiasis by sonography is still largely dependent on the examiner's expertise and differs between 25\% and $100 \%{ }^{[2],[3]}$ One multivariate analysis showed a high predictive value for the presence of CBD stones in patients; aged $>$ or $=55$ yrs. old (Odd ratio (OR) 1.03, jaundice (OR 2.7), elevated alkaline phosphatase (OR 1.002), CBD dilatation on ultrasound (OR 3.8) and CBD stone on ultrasound.[4]

William McKune introduced ERCP in 1968 allowing precise imaging of the biliary and pancreatic ducts. In 1974, German and Japanese scientists used ERCP therapeutically to perform endoscopic sphincterotomy. ${ }^{[5]}$

Since its introduction in 1995 - 96, Magnetic Resonance Cholangiopancreatography (MRCP) has emerged as a noninvasive diagnostic alternative to ERCP for the detection and exclusion of CBD stones. T2 weighted images show the biliary tract as a high signal intensity structure without the use of contrast, instrumentation or ionizing radiation. Stones are seen as low signal intensity structures surrounded by high signal intensity bile.[1] It has been shown that Magnetic Resonance Cholangiopancreatography (MRCP) has a diagnostic accuracy comparable to that of ERCP. MRCP showed $100 \%$ sensitivity and $100 \%$ specificity in a study conducted by Sperlongano $P$ et al.[6] They recommended a greater use of the procedure with avoidance of unnecessary ERCP, which should be reserved for therapeutic purposes only. A study by Loke $\mathrm{M}$ et al also showed a very high diagnostic accuracy of MRCP.[7]

A study was conducted by Jarhult to determine whether even uncomplicated cases of gall stone required a preoperative imaging of the biliary tract by ERCP/MRCP. He randomised two groups of uncomplicated gall stone disease to undergo preoperative MRCP and no imaging. The incidence of common bile duct stones was $3.8 \%$ within the first postoperative year with no statistical difference between the two groups.[8] Thus, routine preoperative evaluation of the bile tree seems unnecessary before laparoscopic cholecystectomy in patients with uncomplicated gallstone disease. As MRCP was an expensive investigation, the need arose to define specific criteria for determining which patients with cholelithiasis required the investigation. Prescribing the investigation to all patients would be considered wasteful with its low predictive value $3.8 \%$ in the above study).[8]

No doubt that ideally all patients with gallstones should undergo preoperative MRCP, not only to rule out CBD stones but also to delineate the biliary tree, but the cost factor is a hindrance. The catch rate being $3.8 \%,{ }^{[8]}$ only it would be a waste of resources. MRCP costs the patient about Rs. 5000 in our setup. Whereas when MRCP is used selectively in some patients fulfilling a set of criteria, the sensitivity is much more. [6] The aim of our study was to evaluate patients of cholelithiasis and to ascertain which case requires MRCP to detect associated choledocholithiasis and to deduce an algorithm to use the diagnostic tool (MRCP) in a cost effective fashion. The objectives were to determine the sensitivity and specificity of MRCP as a diagnostic modality for associated choledocholithiasis; to formulate a set of guidelines and criteria for patients who need to undergo MRCP and to see whether MRCP can replace ERCP as a diagnostic tool for choledocholithiasis.

\section{MATERIALS AND METHODS}

All patients admitted with acute or chronic cholecystitis in the Department of Surgery, KPC Medical College and Hospital between 01.07.2015 and 31.12.2016 (18 Months) were investigated after a thorough clinical examination with biochemical liver function tests and ultrasonography. Magnetic resonance cholangiopancreatography (MRCP) was done only in selected cases. Patients with acalculous cholecystitis were excluded from the study.

Patients with jaundice, raised liver enzymes or history of blood transfusions were investigated for hepatitis B (HbsAg) and hepatitis $\mathrm{C}$ (anti-HCV) to exclude hepatocellular causes of jaundice and raised liver enzymes.

\section{An MRCP was done for Patients who fulfilled at Least one of the Following Criteria}

1. Clinical suspicion of present or past cholangitis.

2. Jaundice not due to hepatocellular causes.

3. Raised liver enzymes, especially alkaline phosphatase.

4. Clinical or biochemical suspicion of present or past gall stone pancreatitis.

5. Dilatation of common bile duct or intrahepatic biliary radicles on USG in presence of gall stone disease.

An evaluation of the sensitivity and specificity of MRCP was done and conclusions were drawn regarding the routine/selective use of the above investigation in patients of cholelithiasis.

Diagnostic ERCP was abandoned in favour of MRCP. In case CBD stones were visible on MRCP, the patient was subjected to ERCP with stone removal followed by laparoscopic cholecystectomy on the following day. In case of failure to remove the CBD stones, the patient was subjected to open choledocholithotomy on the following day.

\section{RESULT}

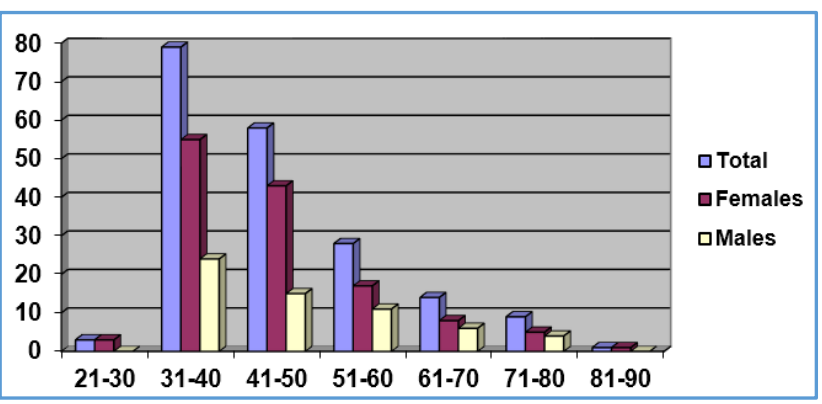

Age Distribution

\begin{tabular}{|c|c|c|c|c|c|c|c|}
\hline Age & 21-30 & 31-40 & $\mathbf{4 1 - 5 0}$ & $\mathbf{5 1 - 6 0}$ & $\mathbf{6 1 - 7 0}$ & $\mathbf{7 1 - 8 0}$ & $\mathbf{8 1 - 9 0}$ \\
\hline Total & 3 & 79 & 58 & 28 & 14 & 9 & 1 \\
\hline Females & 3 & 57 & 45 & 18 & 9 & 5 & 1 \\
\hline Males & 0 & 22 & 13 & 10 & 5 & 4 & 0 \\
\hline \multicolumn{7}{|c|}{ Table 1 } \\
\hline
\end{tabular}

In our period of study, 192 cases of gallstone disease were admitted and treated at our institute. 138 were female and 54 were males. Mean age was 56 years. Range was from 23 yrs. to 86 yrs. There was a female preponderance in all age groups. 


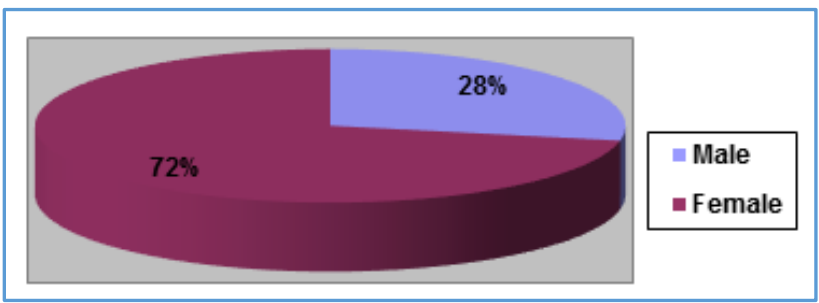

Sex Distribution

\begin{tabular}{|c|c|c|}
\hline Gender & Male & Female \\
\hline Number & 54 & 138 \\
\hline Percentage & $28 \%$ & $72 \%$ \\
\hline \multicolumn{3}{|c|}{ Table 2} \\
\hline
\end{tabular}

$72 \%$ of our study population was female and $28 \%$ was male.

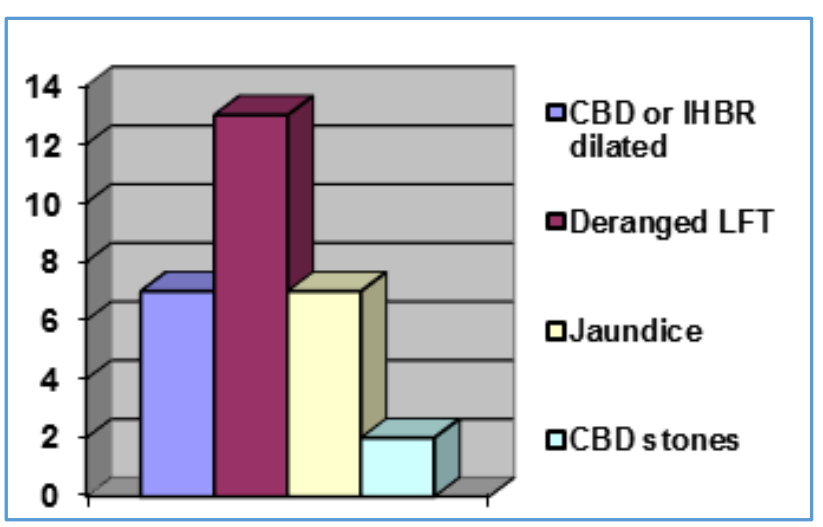

Patients who fulfilled Criteria for further Investigations

\begin{tabular}{|c|c|c|c|}
\hline Criteria & Number & Total & Percentage \\
\hline $\begin{array}{c}\text { CBD or IHBR } \\
\text { dilatation }\end{array}$ & 6 & 17 & 35.29 \\
\hline Deranged LFT & 13 & 17 & 76.47 \\
\hline Jaundice & 7 & 17 & 41.17 \\
\hline \multicolumn{4}{|c|}{ Table 3 } \\
\hline
\end{tabular}

In our study, six out of the seventeen had their CBD or IHBR dilated on USG. Thirteen patients of the seventeen had deranged LFT. Clinical jaundice was present in seven. Some patients had more than one symptom.

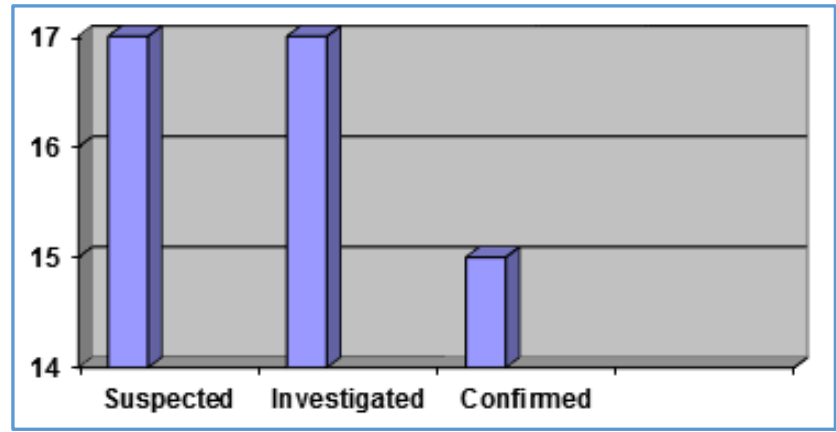

Patients having CBD Stones

\begin{tabular}{|c|c|c|c|}
\hline Suspected & Investigated & Confirmed & $\begin{array}{c}\text { Positive Predictive } \\
\text { Value }\end{array}$ \\
\hline 17 & 17 & 15 & $88.23 \%$ \\
\hline \multicolumn{4}{|c}{ Table 4 } \\
\hline
\end{tabular}

In the course of the study, seventeen patients were suspected to have CBD stones either due to raised LFT, clinical jaundice or USG. Of them, fifteen were confirmed to have CBD stones on MRCP and subsequently were removed by ERCP or choledocholithotomy. There were no false negatives or false positive results. The study showed a positive predictive value of $88.23 \%$.

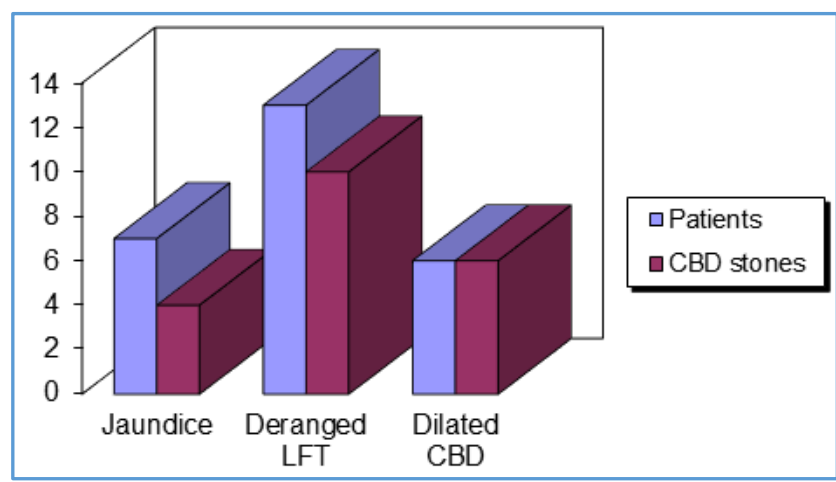

Preoperative Prediction of CBD Stones

\begin{tabular}{|c|c|c|c|}
\hline & Jaundice & $\begin{array}{c}\text { Deranged } \\
\text { LFT }\end{array}$ & $\begin{array}{c}\text { Dilated CBD } \\
\text { (USG) }\end{array}$ \\
\hline Patients & 7 & 13 & 6 \\
\hline CBD Stones & 4 & 10 & 6 \\
\hline Percentage & 57.14 & 76.92 & 100 \\
\hline \multicolumn{3}{|c|}{ Table 5 } \\
\hline
\end{tabular}

In our series, out of the seven patients with jaundice four were found to have CBD stones (57.14\%). Thirteen patients had altered liver function tests, of whom ten harboured CBD stones (76.92\%). All the six patients with dilated CBD in USG were found to have CBD stones (100\%).

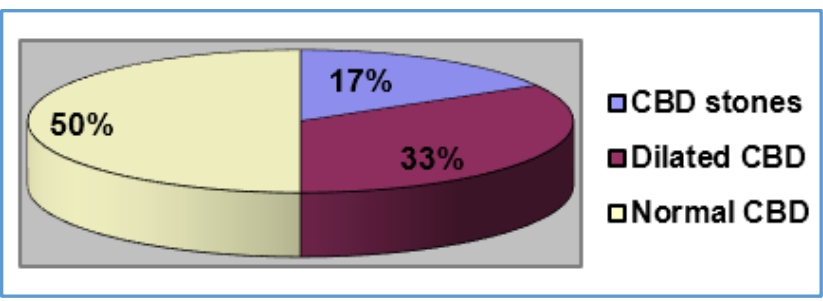

Ultrasound Findings in CBD Stones

\begin{tabular}{|c|c|c|c|}
\hline $\begin{array}{c}\text { USG } \\
\text { Findings }\end{array}$ & $\begin{array}{c}\text { CBD } \\
\text { Stones }\end{array}$ & $\begin{array}{c}\text { Dilated } \\
\text { CBD }\end{array}$ & $\begin{array}{c}\text { Normal } \\
\text { CBD }\end{array}$ \\
\hline Number & 3 & 5 & 9 \\
\hline Percentage & 17.64 & 35.29 & 52.94 \\
\hline \multicolumn{4}{|c|}{ Table 6 } \\
\hline
\end{tabular}

In our series of seventeen patients, the USG findings are summed up as above. Three of the seventeen patients $(17.64 \%)$ were positive for CBD stones on ultrasonography. Five of them (35.29\%) had a dilated CBD on USG. Eight patients (59.24\%) had a normal CBD on USG. 


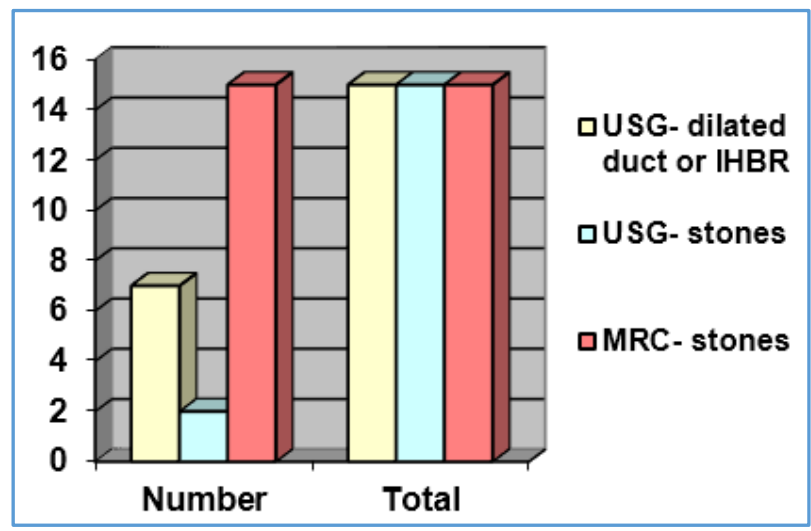

Sensitivity of Ultrasound and MRCP

\begin{tabular}{|c|c|c|c|}
\hline Investigation & Number & Total & Sensitivity \\
\hline $\begin{array}{c}\text { USG- dilated duct } \\
\text { or IHBR }\end{array}$ & 6 & 15 & $40 \%$ \\
\hline USG- stones & 3 & 15 & $20 \%$ \\
\hline MRC- stones & 15 & 15 & $100 \%$ \\
\hline \multicolumn{4}{|c|}{ Table 7 } \\
\hline
\end{tabular}

In our study, out of a total fifteen CBD stones, USG could detect stones in only three cases, but showed duct dilatation in six cases. MRCP could detect CBD stones in all fifteen cases.

In our period of study, 192 cases of gallstone disease were admitted and treated at our institute; 138 were female and 54 were male. Mean age was 56 years. Range was from 23 yrs. to 86 yrs. (Table 1). There was a female preponderance in all age groups. $72 \%$ of our study population was female and $28 \%$ was male. (Table 2) In our study, six out of the seventeen had their CBD or IHBR dilated on USG.

Thirteen patients of the seventeen had deranged LFT. Clinical jaundice was present in seven. Some patients had more than one symptom. (Table 3) In the course of the study, seventeen patients were suspected to have CBD stones either due to raised LFT, clinical jaundice or duct dilatation in USG. Of them fifteen were confirmed to have CBD stones on MRCP and subsequently were removed by ERCP or choledocholithotomy. There were no false negatives or false positive results. The study showed a positive predictive value of $88.23 \%$. (Table 4) In our series, out of the seven patients with jaundice four were found to have CBD stones (57.14\%). Thirteen patients had altered liver function tests, of whom ten harboured CBD stones (76.92\%). All the six patients with dilated CBD in USG were found to have CBD stones (100\%). (Table 5) In our series of seventeen patients the USG findings are summed up as above. Three of the seventeen patients (17.64\%) were positive for CBD stones on ultrasonography. Five of them (35.29\%) had a dilated CBD on USG. Eight patients (59.24\%) had a normal CBD on USG. (Table 6) In our study, out of a total fifteen CBD stones USG could detect stones in only three cases, but showed duct dilatation in six cases. MRCP could detect CBD stones in all fifteen cases. (Table 7) This proved that the set of criteria used in our study, to choose patients who should undergo MRCP; can be used in a cost-effective manner to select patients of cholelithiasis that must undergo further investigations, i.e. MRCP.

\section{DISCUSSION}

During our period of study, 192 cases of gallstone disease were admitted and treated at our institute. Of these, 138 were female. Mean age was 56 years. Range was from 23 yrs. to 86 yrs. Of them 17 patients had at least one clinical, radiological or biochemical indication towards associated CBD stones and underwent further investigations. In our study, 6 out of the 17 had their CBD or IHBR dilated on USG. 13 patients of the 17 had deranged LFT. Clinical jaundice was present in 7. In our series, out of the seven patients with jaundice four were found to have CBD stones (57.14\%). Thirteen patients had altered liver function tests, of whom ten harboured CBD stones (76.92\%). All the eight patients with dilated CBD in USG were found to have CBD stones (100\%).

In our series of seventeen patients, the USG findings are summed up as below. Three of the seventeen patients (17.64\%) were positive for CBD stones on ultrasonography. Seven of them $(35.29 \%)$ had a dilated CBD on USG. Eight patients (59.24\%) had a normal CBD on USG. According to a study by Nuernberg D et al, the sensitivity of sonography in detecting gall stones is very much operator dependant and can be as low as 25\%. Endosonography is much more sensitive (up to 94\%).[2] Our study shows a sensitivity of around $20 \%$ for USG in detecting stones in the CBD. However, sensitivity of detecting dilatation of the hepatobiliary system was much higher, i.e. about $40 \%$.

All 17 subjects were investigated with MRCP to look for CBD stones. Of them 15 were found to have CBD stones in association with gall bladder stones. So our study shows a positive predictive value of $88.23 \%$ (15 out of 17) for MRCP in suspected CBD stones when patients with selected criteria were subjected to the test. It also shows $100 \%$ sensitivity and $100 \%$ specificity for the same. MRCP showed $100 \%$ sensitivity and $100 \%$ specificity in a study conducted by Sperlongano $P$ et al.[6] So MRCP can be recommended for all patients who meet the selection criteria. However, we find that if MRCP was done for all patients who do not meet the selection criteria then MRCP would only have a positive predictive value of $7.81 \%$ (15 out of 192), which would be a waste of resources as MRCP is an expensive test. A study by Jarhult J recruited 312 patients intended for laparoscopic cholecystectomy who were randomly allocated to undergo preoperative radiology (intravenous cholangiography or magnetic resonance cholangiography) or to a control group. Intraoperative cholangiography was not used routinely in either group. There was no bile duct injury and no difference in complication frequency between the two groups. The incidence of common bile duct stones was 3.8\% within the first postoperative year with no statistical difference between the two groups. So their conclusion was that routine preoperative evaluation of the bile tree seems unnecessary before laparoscopic cholecystectomy in patients with uncomplicated gallstone disease. ${ }^{[8]}$ Our study corroborates the above findings.

A study by Charatcharoenwitthaya $P$ et al concluded that ERCP had a high predictive value in patients with jaundice, elevated alkaline phosphatase or CBD dilatation on sonography.[4] But a study by Sperlogano $\mathrm{P}$ et al concluded that MRCP has a diagnostic accuracy comparable to that of ERCP and thus recommended ERCP to be reserved for therapeutic procedures only.[6] Their conclusion was confirmed by a study conducted by Kim Y J et al, which 
concluded that MRCP in patients with a moderate or high risk of CBD stones can reduce the number of purely diagnostic ERCPs and hence the complications associated with it.[9] Another similar study by Welbourn CR et al showed a positive predictive value up to $77 \%$.[10] $^{[10}$ study shows a high positive predictive value for MRCP in patients with risk factors for choledocholithiasis (88.23\%).

Of the other 175 patients, 162 underwent laparoscopic cholecystectomy and 13 underwent open cholecystectomy. A study by Ausch C et al recommends MRCP as a screening tool for all cases of laparoscopic cholecystectomy,[11] but our study does not prove this method of screening to be cost effective.

A study by Ainsworth AP et al concludes that in a patient population with a possibility of therapeutic ERCP in 50\% cases, ERCP was the most cost effective study.[12] However, we are of the opinion that only MRCP should be used as a diagnostic tool and ERCP when there is a $100 \%$ probability of therapeutic intervention.

A study by Kalthenheler E, University of Sheffield, UK concludes that MRCP is not only comparable to ERCP as a diagnostic tool as far as accuracy is concerned, but also results in reduced cost and improved quality of life.[13] Our study does corroborate the above finding.
However, since all fifteen cases that were suspected were finally found to be harbouring CBD stones; the significance of the study was reduced. Another lacuna in our study remains in that MRCP was not compared with ERCP in a randomised controlled trial; as ours was not a comparative study. But most studies show that non-invasive MRCP is as good as ERCP, which is an invasive procedure with its own set of complications when used as a diagnostic tool. MRCP being non-invasive has no therapeutic potential; and ERCP remains the only option when an intervention is required.

\section{Summary}

Although very effective, performing an MRCP on all patients who were to undergo cholecystectomy is not cost effective and waste of resources. The positive predictive value is about 7.8\% (according to our study) in such a situation. The incidence was about $4 \%$ in another study. ${ }^{[8]}$ But when MRCP was done only in selected patients, i.e. those with clinical, radiological and biochemical risk factors for CBD stones. The positive predictive value was found to be $88.23 \%$ in our study. The sensitivity and specificity of MRCP was $100 \%$. So, an algorithm was formulated to determine a protocol for investigating patients with gall stone disease and determine when to use MRCP/ERCP.

\section{Algorithm}

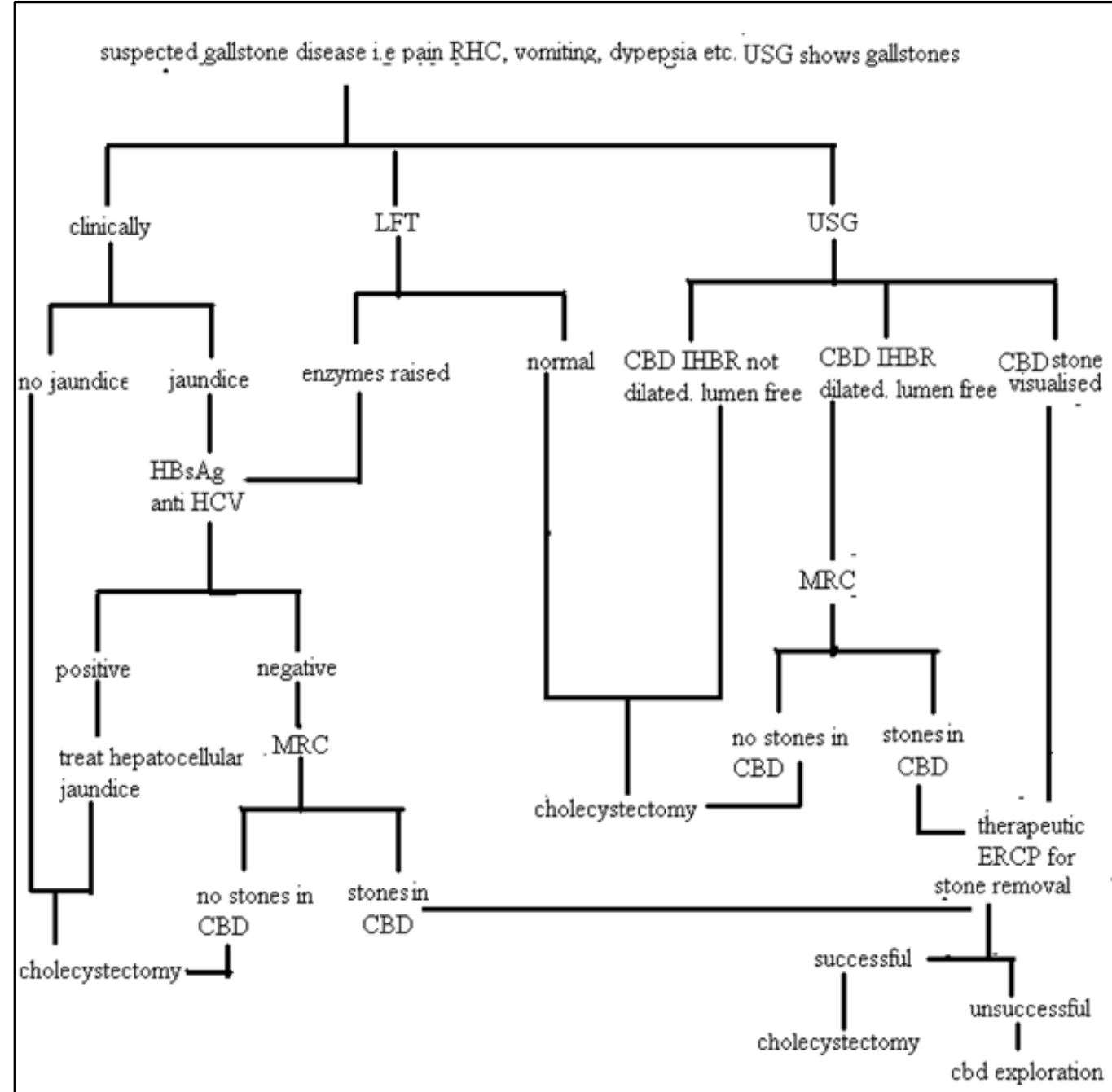




\section{CONCLUSION}

The following Conclusions were reached from the study

1. Subjecting all patients of cholelithiasis to further expensive investigations (MRCP) for associated choledocholithiasis is unnecessary and not cost effective.

2. Only those patients satisfying the well-defined criteria as postulated in the algorithm may be investigated for associated choledocholithiasis.

3. ERCP, being an invasive procedure with its established set of complications should not be used as a purely diagnostic tool.

4. MRCP is a very good diagnostic tool for imaging the CBD and when used within its defined criteria has a very high positive predictive value $(88.23 \%$ in our study) for CBD stones.

5. MRCP showed $100 \%$ sensitivity and specificity in our study.

6. Diagnostic ERCP should be replaced by MRCP.

7. However, ERCP with its therapeutic potential of extracting CBD stones and performing sphincterotomies should be offered to patients with diagnosed or retained CBD stones.

\section{REFERENCES}

[1] McFadden DW, Nigam A. Choledocholithiasis and cholangitis. In: Zinner MJ, Ashley SW. eds. Maingot's abdominal operations. $11^{\text {th }}$ edn. McGraw-Hill 2007:865-79.

[2] Nuernberg D, Ignee A, Dietrich CF. Ultrasound in gastroenterology. Biliopancreatic system. Med Klin (Munich) 2007;102(2):112-26.

[3] Einstein DM, Lapin SA, Ralls PW, et al. The insensitivity of sonography in the detection of choledocholithiasis. AJR Am J Roentgenol 1984;142(4):725-8.

[4] Charatcharoenwitthaya P, Sattawatthamrong Y, Manatsathit S, et al. Predictive factors for synchronous common bile duct stone in patients with symptomatic cholelithiasis. J Med Assoc Thai 2004;87(2):131-6.
[5] Lin E, Fink AS. Endoscopy and endoscopic intervention. In: Zinner MJ, Ashley SW. eds. Maingot's abdominal operations. $11^{\text {th }}$ edn. McGraw-Hill 2007; P. 48.

[6] Sperlongano P, Pisaniello D, Del Viscovo L, et al. Efficacy of magnetic resonance cholangiopancreatography in detecting common bile duct lithiasis: our experience. Chir Ital 2005;57(5):635-40.

[7] Loke M, Endes J, Abasiute G. The part of MR cholangiography in biliary surgery. Acta Chir Hung 1997;36(1-4):198-200.

[8] Jarhult J. Is preoperative evaluation of the biliary tree necessary in uncomplicated gallstone disease? Results of randomized trial. Scand J Surg 2005;94(1):31-3.

[9] Kim YJ, Kim MJ, Kim KW, et al. Preoperative evaluation of common bile duct stones in patients with gallstone disease. AJR Am J Roentgenol 2005;184(6):1854-9.

[10] Welbourn CR, Haworth JM, Leaper DJ, et al. Prospective evaluation of ultrasonography and liver function tests for preoperative assessment of the bile duct. Br J Surg 1995;82(10):1371-3.

[11] Ausch C, Hochwarter G, Taher M, et al. Improving the safety of laparoscopic cholecystectomy: the routine use of preoperative magnetic resonance cholangiography. Surg Endosc 2005;19(4):574-80.

[12] Ainsworth AP, Rafaelsen SR, Wamberg PA, et al. Costeffectiveness of endoscopic ultrasonography, magnetic resonance cholangiopancreatography and endoscopic retrograde cholangiopancreatography in patients suspected of pancreaticobiliary disease. Scand J Gastroenterol 2004;39(6):579-83.

[13] Kaltenthaler E, Vergel YB, Chilcott J, et al. Systematic review and economic evaluation of magnetic resonance cholangiopancreatography compared with diagnostic endoscopic retrograde cholangiopancreatography. Health Technol Assess 2004;8(10):iii, 1-89. 